\title{
Induction and Analysis of Cytotoxic T-Lymphocytes that Recognize Autologous Oral Squamous Cell Carcinoma
}

\author{
JUN-YA OKAMOTO ${ }^{1}$, AKIHIRO MIYAZAKI ${ }^{1}$, JUN-ICHI KOBAYASHI $^{1}$, \\ SHO MIYAMOTO ${ }^{1,2}$, TAKANORI SASAKI ${ }^{1}$, TAKAYUKI KANASEKI ${ }^{2}$, \\ YOSHIHIKO HIROHASHI ${ }^{2}$, TOSHIHIKO TORIGOE ${ }^{2}$ and HIROYOSHI HIRATSUKA ${ }^{1}$ \\ Departments of ${ }^{1}$ Oral Surgery, and ${ }^{2}$ Pathology, Sapporo Medical University School of Medicine, Sapporo, Japan
}

\begin{abstract}
Background: It is essential that cytotoxic T-lymphocytes (CTLs) recognize tumor-associated antigens (TAAs) and exhibit antitumor effects in immunological responses for tumor rejection. However, only a few cases with oral squamous cell carcinoma (OSCC) have been studied for these antitumor mechanisms. We established a cancer cell line and autologous CTL pair for identifying TAAs in OSCC, despite difficulties in establishing such a pair. Materials and Methods: A cell line (OTM) from a primary lesion and a CTL line (TCOTM) were derived from OSCC in a 64-year-old female patient. CTL clones were generated by repetitive limiting dilutions. Accurate characterization was performed by in vitro analysis. Results: The TcOTM clone showed specific cytotoxic activity against OTM cells in an human leukocyte antigen (HLA)-A24-restricted manner. Furthermore, it exerted cytotoxicity against the allogenic HLA-A24 cell lines. Conclusion: These data indicated that the TcOTM clone recognized a TAA presented by HLA-A24 cells. This unique method will allow for identification of unknown TAAs for OSCC in the future.
\end{abstract}

Oral cancer is the sixth most common cancer and its incidence is continuously increasing (1). Currently, it is possible to achieve high rates of positive outcomes by surgery or radiotherapy without functional complications and esthetic problems in early-stage oral cancer (2). However, in locally advanced or recurrent oral cancer, although the combination of surgery, radiotherapy, and chemotherapy has been found to be more effective than single-modality therapy, this combination treatment has failed to produce

Correspondence to: Akihiro Miyazaki, DDS, Ph.D., Department of Oral Surgery, Sapporo Medical University School of Medicine, South-1, West-16, Chuo-ku, Sapporo 060-8543, Japan. Tel: +81 116889673, Fax: +81 116417151, e-mail: amiyazak@sapmed.ac.jp

Key Words: Oral cancer, CTL, tumor antigen, autologous tumorCTL pair, HLA-A24, oral squamous cell carcinoma. remarkable increases in overall survival or recurrence-free survival rates because of locoregional recurrence and distant metastasis (2). Therefore, advances in new therapeutic modalities for patients with locally advanced or recurrent oral cancer are urgently needed. As a new treatment method, cetuximab is currently the main monoclonal antibody approved for the management of squamous cell carcinoma (SCC) of the head and neck including oral squamous cell carcinoma (OSCC), but other strategies such as immune checkpoint inhibitors are attracting a great deal of attention $(3,4)$. In particular, immune checkpoint openers offer promising outcomes for the treatment of head and neck SCC, although their clinical responses may be restricted (5).

Indeed, since the discovery of the first human tumorassociated antigen (TAA) in 1991, cancer vaccines have shown promise in pilot clinical studies (6-10). Previously, our group identified an human leukocyte antigen (HLA)-A24-restricted antigenic peptide, survivin-2B80-88 (AYACNTSTL), that is recognized by $\mathrm{CD}^{+}$cytotoxic T-lymphocytes (CTLs) and functions as an immunogenic molecule in patients with cancer of various histological origins and immunological responses (11). In OSCC, we conducted a phase I clinical study to evaluate the safety and the efficacy of survivin-2B80-88 peptide vaccination in HLA-A24-positive patients, revealing that survivin-2B peptide vaccination was safe and had therapeutic potential (12).

In another study, we also established a novel autologous tumor-CTL pair of OSCC which recognized tumor cells in an HLA-A24-restricted manner (13). However, little is known about TAAs recognized by autologous CTLs in OSCC, and very few attempts have been made at identifying these yet-unknown TAAs because the establishment of such autologous pairs of tumor cell lines and CTLs requires great effort. Therefore, in this study, we aimed to establish and analyze an autologous tumor-CTL pair of OSCC that was capable of identifying a novel HLA-A24-restricted TAA in OSCC. Recently, cancer stem-like cells (CSCs)/tumorinitiating cells (TICs) that are essential for tumor maintenance, recurrence, and distant metastasis have been 
extensively studied (14-17). The results of the establishment of an autologous tumor-CTL pair, which is the aim of our present study, will contribute to improvements in CSC/TICtargeting immunotherapy due to identification of natural antigen peptide (NAP) from the tumor cell lysate that can be recognized by autologous CTLs. Such improvements in CSC/TIC-targeting immunotherapy for OSCC will lead to development of more effective peptide vaccine therapies.

\section{Materials and Methods}

Cell lines and primary culture. The OSCC cell line, OTM, was established from biopsy specimens resected from a 64-year-old female patient with moderately differentiated OSCC and was cultured in Dulbecco's modified Eagle's medium/Ham's F12 medium (Life Technologies, Carlsbad, CA, USA). The HLA genotype of the OTM cells was HLA-A*2402/2603, B*4001/5101, C*1402/1502. OSCC cell lines OSC19 (HLA-A2) and OSC70 (HLA-A24) were also established in our laboratory (18). HSC-2 (HLA-A24) OSCC cell lines were purchased from the Human Science Research Resources Bank (Osaka, Japan). Erythroleukemia cell line K562 was purchased from the American Type Culture Collection (ATCC, Manassas, VA, USA). The HSC-2, OSC19, OSC70, and K562 cell lines were cultured in RPMI-1640 medium (Sigma-Aldrich, St Louis, MO, USA). All the media were supplemented with $10 \%$ fetal bovine serum (Invitrogen, Palo Alto, CA, USA) and $1 \%$ penicillin, and all the cultures were carried out in a $5 \% \mathrm{CO}_{2}$ incubator at $37^{\circ} \mathrm{C}$.

Flow cytometric analysis and monoclonal antibodies. The cells were incubated with murine monoclonal antibodies (mAbs) at saturating concentration for $30 \mathrm{~min}$ on ice, washed with phosphate-buffered saline, and stained with a polyclonal goat anti-mouse antibody coupled with fluorescein isothiocyanate for $30 \mathrm{~min}$. The samples were then analyzed using a BD LSR II flow cytometer with FACS Calibur (Becton Dickinson Biosciences, Mountain View, CA, USA). AntiHLA-ABC (W6/32; AbD Serotec), anti-HLA-DR (L243; ATCC), and anti-HLA-A24 (C7709A2; a gift from Dr. P. G. Coulie, Ludwig Institute for Cancer Research, Brussels, Belgium) mAbs were used.

CTL induction and establishment of CTL clones. Autologous peripheral blood mononuclear cells (PBMCs) from the OTM donor patient were subjected to density gradient centrifugation with Lymphoprep (Axis Shied, Oslo, Norway) and frozen at $-80^{\circ} \mathrm{C}$ for storage.

Mixed lymphocyte tumor cell (MLTC) culture was performed as described previously (19). Briefly, CD8 ${ }^{+} \mathrm{T}$-cells were positively separated from the OSCC patient's PBMCs using immunomagnetic beads coupled with an anti-CD8 mAb (Miltenyi Biotech $\mathrm{GmbH}$, Germany) following the manufacturer's protocol. Then, $2 \times 10^{6}$ $\mathrm{CD}^{+}$T-cells were co-cultured in a 24 -well plate with $2 \times 10^{5}$ irradiated OTM cells as antigen-presenting cells in $2 \mathrm{ml}$ of AIM-V medium (Invitrogen Life Technologies, Carlsbad, CA, USA) supplemented with 10\% human serum (Filtron, Brooklyn, NSW, Australia). Three days later, human recombinant interleukin-2 (rIL2; Takeda Pharmaceutical Co., Osaka, Japan) was added at a final concentration of $20 \mathrm{IU} / \mathrm{ml}$. The same MLTC culture procedure was performed every 7 days. After stimulation four times, the cytotoxic activity and interferon-g (IFN $\gamma$ ) secretion were measured using the lactate dehydrogenase (LDH) release cytotoxicity assay and ELISpot assay, respectively, as described below.

In order to obtain the CTL clones, standard limiting dilution was performed as described previously $(20,21)$. The series of diluted CTLs $\left(1 \times 10^{4}\right)$ were then incubated with 100 Gy-irradiated $5 \times 10^{4}$ allogeneic PBMCs as feeder cells in $200 \mu \mathrm{l}$ of AIM-V medium supplemented with $10 \%$ human serum and $100 \mathrm{U} / \mathrm{ml}$ rIL2 in 96-well round plates. The allogenic PBMCs as feeder cells were isolated from three healthy volunteer donors using Lymphoprep isolation of CD8 ${ }^{+}$ cells, and establishment of phytohemagglutinin (PHA; $5 \mu \mathrm{g} / \mathrm{ml}$; Wako Chemicals, Osaka, Japan) blast was performed as described. CD8+ Tcells were stimulated with a peptide-pulsed PHA blast once in 2 weeks. On day 7, half of the culture medium was replaced with AIM$\mathrm{V}$ medium supplemented with $10 \%$ human serum and $100 \mathrm{U} / \mathrm{ml} \mathrm{rIL} 2$. Growing wells were observed on days 14-20. The cells were then transferred to 24-well culture plates, and the specific cytotoxic activity was examined using the LDH release cytotoxicity assay.

For the first limiting dilution, CTLs were distributed among 45 wells in 24-well plates, and for the second dilution, CTLs were distributed among 31 wells. Theoretically, co-culturing CTLs and OTM cells that have become a single clone should help verify the cytotoxic activity of the CTLs using the ELISpot assay. Accordingly, on day 14 , we assessed the reactivity of the $\mathrm{CD} 8^{+} \mathrm{T}$-cells using IFN $\gamma$ enzyme-linked ELISpot assay. The cytotoxic activity of the T-cells was assessed using the $\mathrm{LDH}$ release cytotoxicity assay.

Interferon- $\gamma$ ELISpot assay. Multiscreen 96-well plates were coated with $100 \mathrm{~mL} /$ well of $5 \mathrm{mg} / \mathrm{mL}$ anti-IFN-g capture antibody (Becton Dickinson Biosciences) in PBS at $4^{\circ} \mathrm{C}$ overnight. Plates were washed once with $200 \mathrm{~mL} /$ well complete RPMI 1640 and blocked with $200 \mathrm{~mL} /$ well complete RPMI 1640 at room temperature for 2 hours. Then $5 \times 10^{4}$ CTLs were incubated with $5 \times 10^{4} /$ well target cells. After 24 -hour incubation at $37^{\circ} \mathrm{C}, \mathrm{IFN}-\gamma$ spots were developed and counted as per the manufacturer's instructions.

$L D H$ release cytotoxicity assay. The antigen-specific lytic activity of the CTL clones was evaluated using an LDH Cytotoxicity Detection Kit (Takara Bio, Otsu, Japan) following the manufacturer's protocol. OTM cells $\left(10 \times 10^{3}\right.$ cells/well $)$ were incubated with different numbers of CTL clone cells for $7 \mathrm{~h}$ at $37^{\circ} \mathrm{C}$ in 96 -well V-bottomed plates, and the cytotoxicity was calculated using the culture supernatants. The percentage of specific lysis was calculated as [(experimental release - spontaneous release) /(maximum release - spontaneous release)] $\times 100$. Cytotoxicity blocking assays were performed using mAbs. Tumor targets were incubated with the hybridoma culture supernatants of anti-HLA-class I mAb (W6/32), anti-HLA-A24 mAb (C7709A2), anti-HLA-A1, A11, A26 mAbs (8.L.101), and anti-HLA$\mathrm{DR} \mathrm{mAb}$ (L243) for $1 \mathrm{~h}$ at room temperature.

The experiments conducted in the present study were approved under the institutional guidelines for the use of human subjects in research (Approval No. 23-117). The patients and their families, as well as the healthy donors, provided their informed consent for the use of blood samples and tissue specimens in our research.

\section{Results}

Establishment of the OSCC cell line, OTM. A new OSCC cell line was established in order to identify TAAs. As shown in Figure 1A, a biopsy specimen of carcinoma of the right buccal 

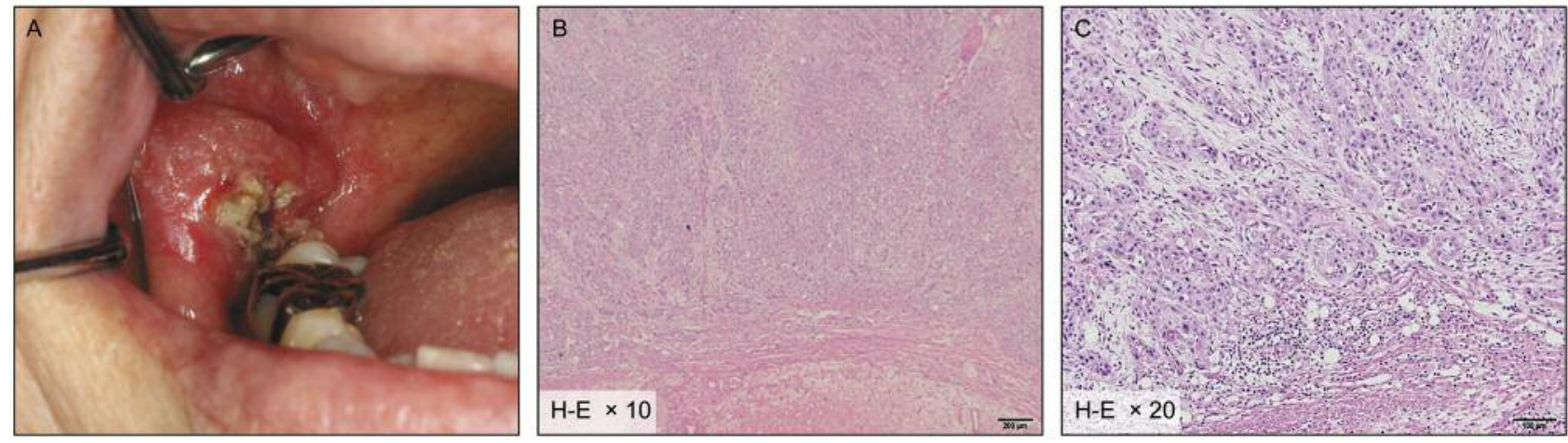

Figure 1. Right buccal mucosa cancer in a 64-year-old woman. A: Gross appearance. Tumor was T2N1MO (stage III) with size of $24 \times 22 \mathrm{~mm}$. B, $C$ : Result of the biopsy and histopathological images revealed moderately differentiated squamous cell carcinoma; mode of invasion was YK-4C. $H$-E: Hematoxylin and eosin stain.
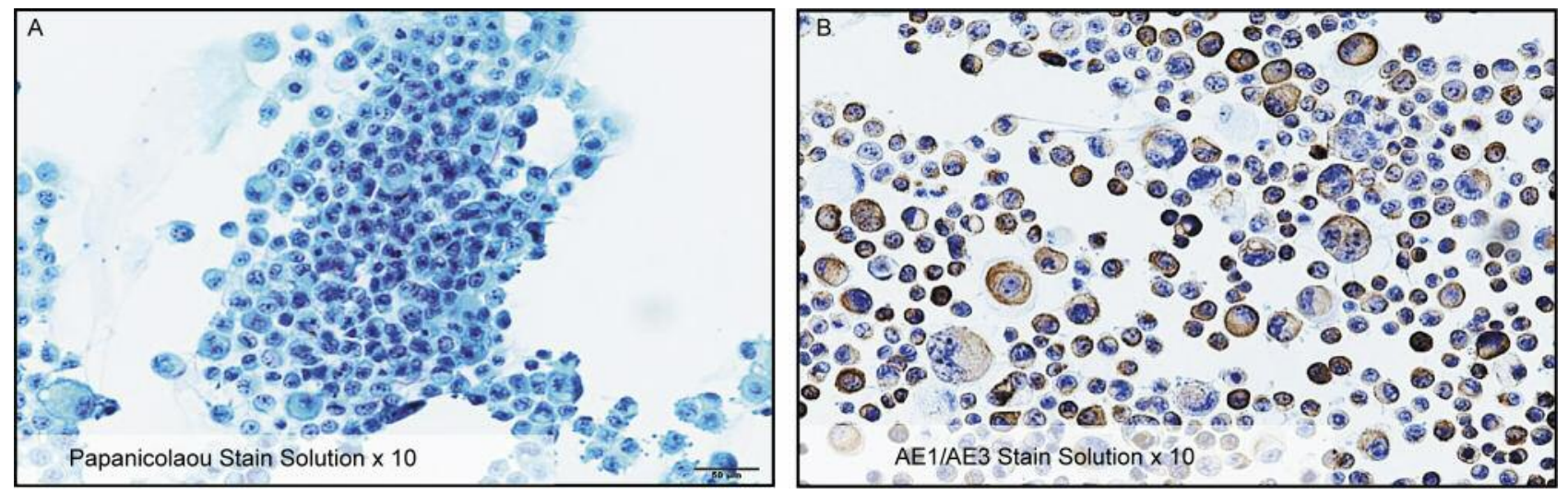

Figure 2. A: Papanicolaou staining of tumor biopsy tissue showed an increase in the nuclear/cytoplasmic ratio and aggressive nuclear fission. B: Additional immunohistochemical studies revealed atypical cells as positive for AE1/AE3 (pancytokeratin).

mucosa from a 64-year-old woman patient was cultured and the OSCC cell line, OTM, was successfully established. The primary lesion of the carcinoma specimen was a moderately differentiated SCC (Figure 1B and C) and revealed a 4C mode of invasion, which was diffuse invasion of cord-like type, according to the Y-K classification (22). Papanicolaou staining showed an increase in the nuclear/cytoplasmic ratio and aggressive nuclear fission (Figure 2A). Additional immunohistochemical studies revealed atypical cells as positive for AE1/AE3 (pancytokeratin) (Figure 2B). The cell line had a standard doubling time of $48 \mathrm{~h}$ and grew stably through more than 20 passages (Figure 3). Moreover, this cell line exhibited tumor-forming ability in severe combined immunodeficiency (SCID) mice, and the tumors were typical SCC resembling the primary lesion (Figure 4). For immunological evaluation of the OTM cell line, the expression of surface major histocompatibility complex molecules was then examined by flow cytometric analysis. As shown in Figure 5, the OTM cells expressed a pan-HLA class I molecule (W6/ 32) and HLA-A24 (C7709A2), but no detectable expression of HLA-A2 (BB7.2) and HLA-DR (L243) was observed. These HLA expression profiles suggested that immune cells would be able to interact with OTM cells through HLA-class I molecules.

Induction and analysis of CTLs and establishment of TcOTM clones. In order to establish CTLs that recognized the OTM cells, we stimulated PBMCs with autologous OTM cells several times. The specific reactivity was then evaluated using the Interferon- $\gamma$ ELISpot assay (Figure 6). The CTL line (TcOTM) recognized autologous OTM cells specifically, but not cells of the erythroleukemia cell line K562, which were used as a negative control. For detailed analysis of the TcOTM clones, they were generated using the standard limiting dilution 

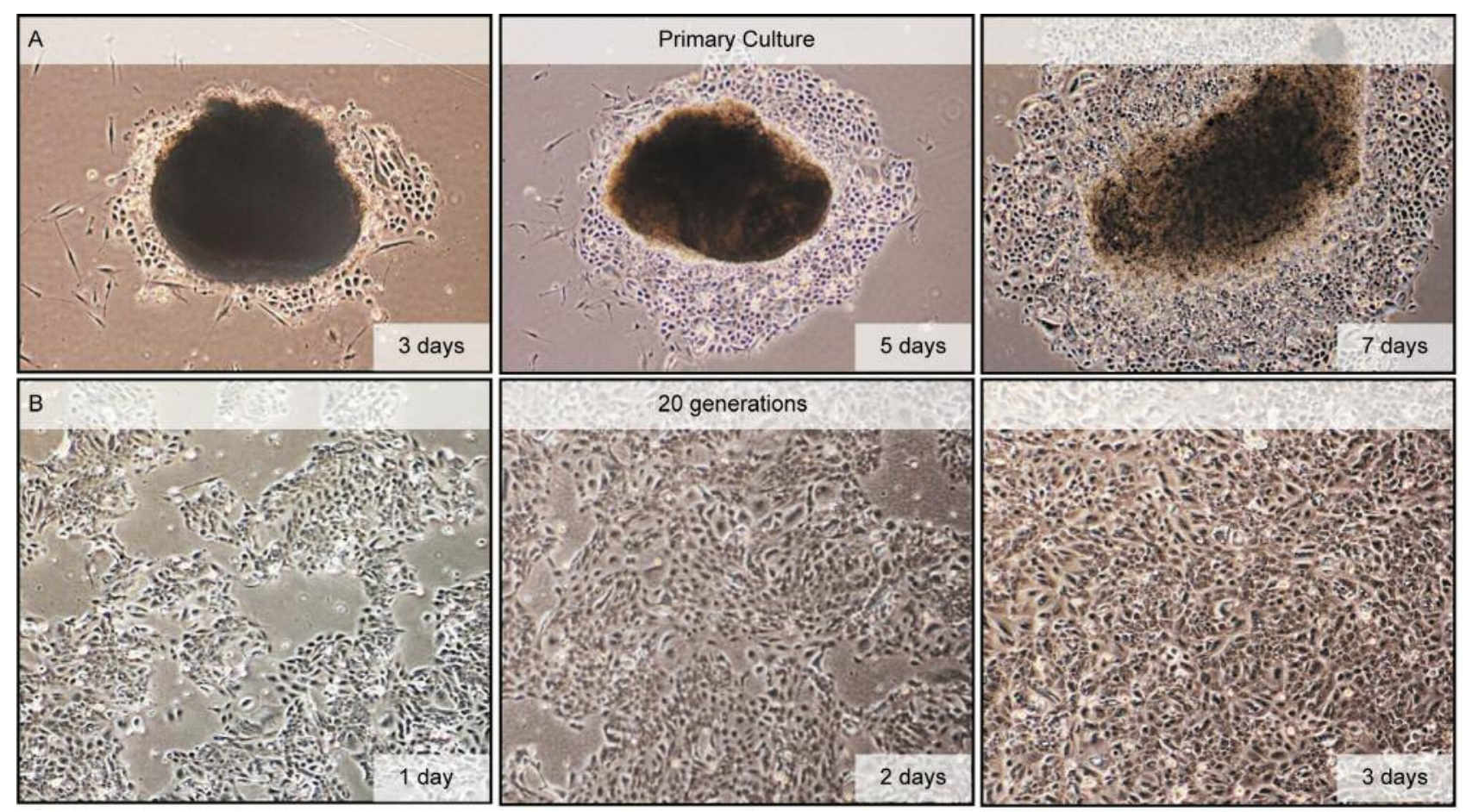

Figure 3. Image of the culture of a portion of the biopsy tissue, as observed under a phase-contrast microscope (x40). A: After culture for 3, 5, and 7 days. B: Repeated passages, taking stock of 20 generations each day; the cells showed stable proliferation.
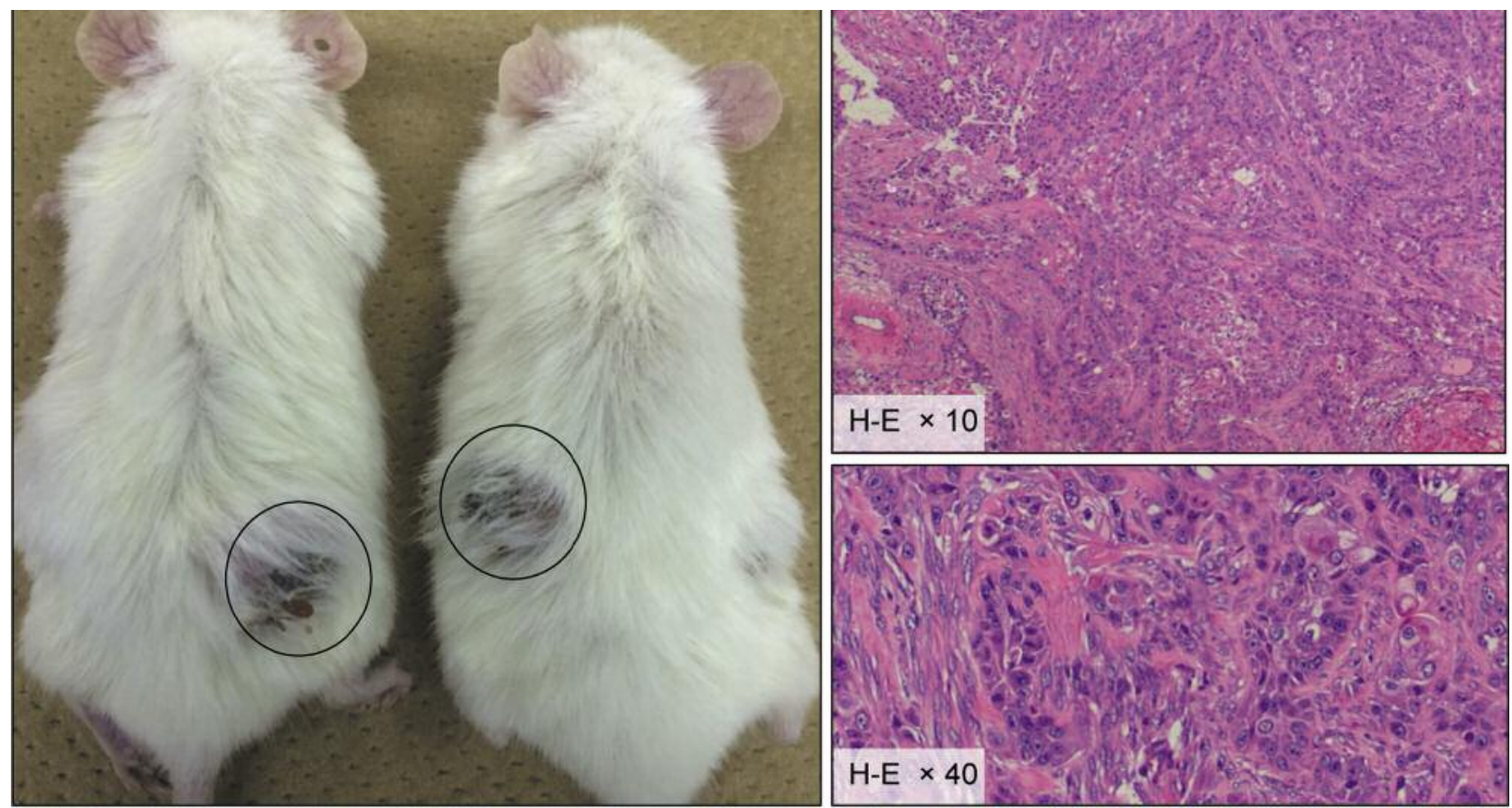

Figure 4. The novel oral squamous cell carcinoma cell line, OTM, exhibited tumor-forming ability in severe combined immunodeficiency (SCID) mice, and the tumors were typical squamous cell carcinomas resembling the primary lesion. A: Subcutaneous injection of cultured cancer cells $\left(1.0 \times 10^{4}\right) / \mathrm{ml}$ suspended to $1 \mathrm{ml}$ in the back of an SCID mouse strain. After 30 days of culture, tumor formation was observed on the back of the mouse. B: Excision of resultant tumor tissue, and histopathological examination revealed squamous cell carcinoma. H-E: Hematoxylin and eosin stain. 


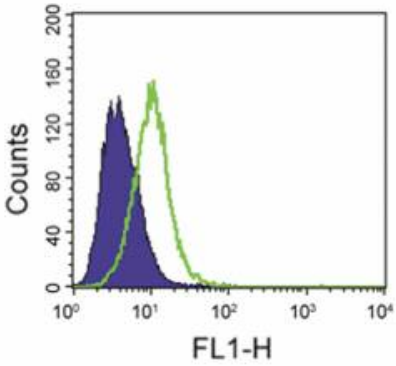

HLA-Class I (W6/32)

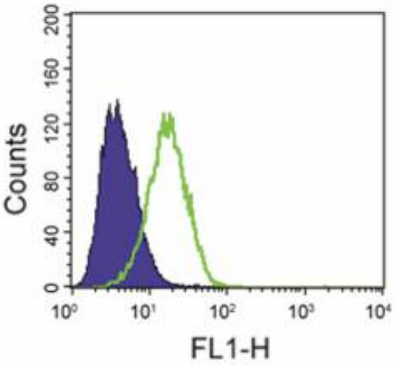

HLA-A24 (C7709A2)

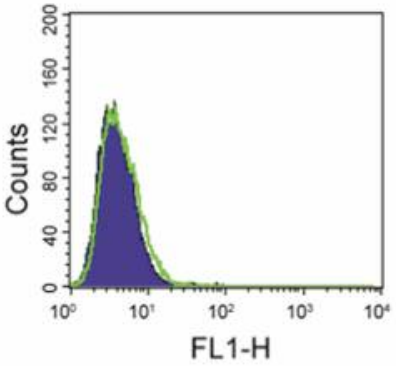

HLA-A2 (BB7.2)

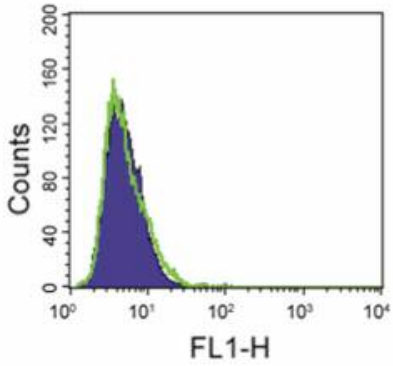

HLA-Class II (L243)

Figure 5. FACScan analysis of the surface human leukocyte antigen (HLA) molecules expressed by the OTM cell line. HLA-class I mAb (W6/32), HLA-A24 mAb (C7709A2), HLA-A2 mAb (BB7.2), and HLA-DR mAb (L243) were used for specific detection. The OTM cell expressed pan-HLA Class I and HLA-A24 molecules.

method, and we successfully established a CTL clone, designated as CTL3. As shown in Figure 7, CTL3 recognized the autologous OTM cells specifically but did not recognize K562 cells, which were used as a negative control. Furthermore, the specific reactivity was evaluated using the LDH release cytotoxicity assay (Figure 8). CTL3 exerted a cytotoxic potential on OTM cells in a dose-dependent manner. Next, we performed limiting dilution again for the establishment of a single TcOTM clone and identified the most positive spot in the group of CTL 3 clone 1 (3-1) (Figure 9).

Next, in order to identify the HLA restriction of elements, blocking assays using several mAbs were performed against CTL3-1. As shown in Figure 10, the cytotoxic activity of clone CTL3-1 was blocked by the use of anti-HLA-class I $\mathrm{mAb}(\mathrm{W6} / 32)$ and HLA-A24 mAb (C7709A2), but not by anti-HLA-A26 mAb (ab33883) or anti HLA-DR mAb (L243), which indicated that clone CTL3-1 was an HLAA24-restricted CTL. For further analysis of CTL3-1, we measured its cytotoxic activity against allogenic OSCC cell lines using the LDH release cytotoxicity assay (Figure 11). CTL3-1 recognized allogeneic HLA-A24-positive OSCC cells such as HSC-2 and OSC-70, as well as the autologous OTM cells, but did not recognize OSC-19 (HLA-A2) cells. These data indicate that CTL3-1 recognized a shared antigen in an HLA-A24-restricted manner.

\section{Discussion}

OSCC is one of the most common types of human cancers worldwide. The establishment of cell lines from human cancer is important for investigating the biology of cancer cells at the cellular level. However, human OSCCs are generally difficult to establish in culture as cell lines (18). Three major factors have been suggested to be responsible for the failure of establishment of such cell lines: fungal or bacterial contamination, overgrowth of fibroblasts, and inadequate nutrients in the culture medium (23).

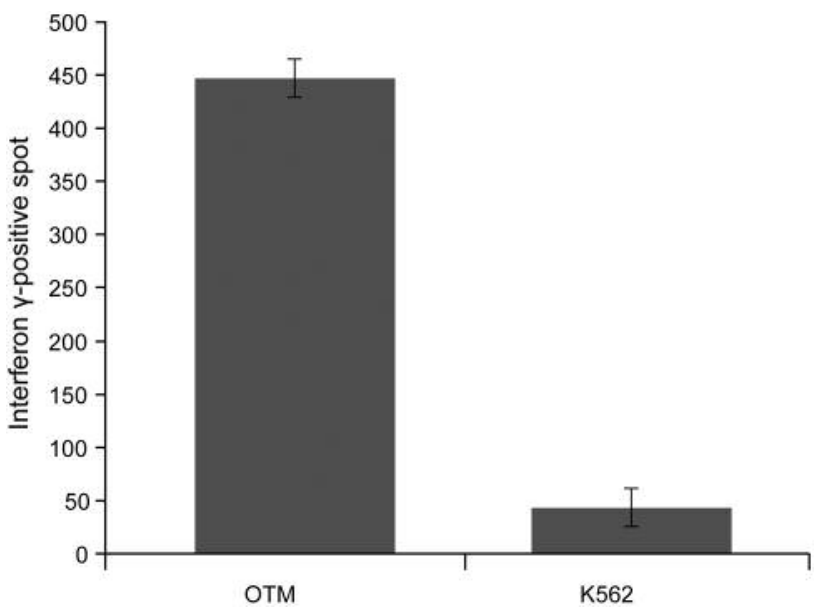

Figure 6. Cytotoxic activity of the TcOTM CTL line. Blood collected from the same patient was used to establish OTM cells. Centrifugation was used to separate the CD8+ lymphocytes using microbeads. For coculture, TcOTM was separated from the OTM CD8+ lymphocytes, and the cytotoxic activity was measured using ELISpot Assay. High specific cytotoxic activity towards OTM cells can be clearly seen. The K562 cell line was used as negative control.

Previously, we have also made many efforts to establish cell lines from human OSCCs $(13,18,24)$. In this study, using approximately 20 biopsy or surgically-resected specimens of different patients with OSCCs, finally we succeeded in establishing only one cell line (OTM). Furthermore, we successfully established the CTL line TcOTM, which reacts with autologous OTM cells established from the PBMCs of one patient by using MLTC. We also found that the TcOTM clone specifically recognized the allogenic OSCC cell lines OSC-70 and HSC-2 as well as the autologous OTM cell line. We also found that the OTM, OSC-70, and HSC-2 cells shared a TAA in a HLA-A24-restricted manner, as the cytotoxic 


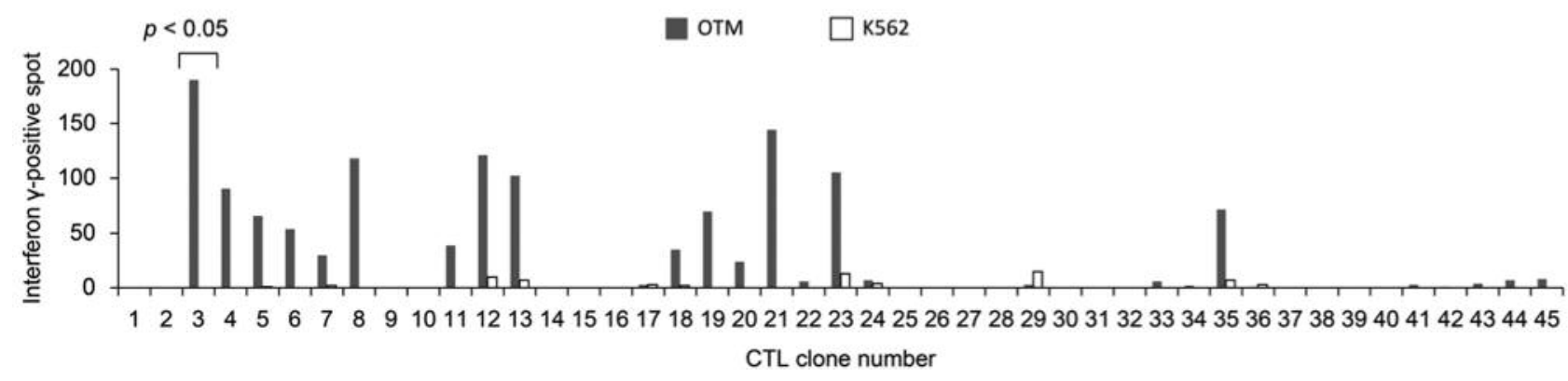

Figure 7. Limiting dilution of bulk TcOTM cells. Limiting dilution was used, but there was a different reaction in each well. The most positive spot was found for CTL clone 3. The K562 cell line was used as negative control.

activity of the TcOTM clone was clearly inhibited with the use of the anti-HLA-A24 mAb. Although the HLA-A24restricted TAA that was recognized by the TcOTM clone has not yet been identified, it shows potential for further development toward clinical applications.

Several approaches for identifying TAAs are known. Novel TAAs have been identified at our institute using methods such as gene expression cloning, bioinformatics, reverse immunology, transcriptome analysis, and peptidome analysis. In particular, peptidome analysis enabled the biochemical analysis of NAP in living cells using an autologous tumor-CTL pair (25-27). With this progress, we started a clinical trial for cancer vaccine therapy using an antigenic peptide derived from one of the inhibitor of apoptosis protein family members, surviving, using a reverse immunology method $(12,28-30)$. Some patients showed decreases in tumor marker expression and remarkable tumor regression. These findings suggested that cancer vaccine therapy might also be effective for patients with OSCC. Meanwhile, other clinical trials of multiple peptide vaccinations for patients with HLA-A24-positive advanced OSCC have revealed induction of immune responses and improved overall survival (31). Therefore, it is necessary to accumulate a large number of available peptides with regard to HLA typing. HLA-A24 is the most common HLA class I allele in the Japanese population, and $60 \%$ of Japanese individuals $(95 \%$ of whom have an $A * 24: 02$ genotype), $20 \%$ of Caucasians, and $12 \%$ of Africans have been found to be positive for HLA-A24 (32). Therefore, in the future, we need to identify new TAAs that are mainly HLA-A24-restricted or other HLA class I allelerestricted. Our autologous tumor-CTL pair model established in the present study would be very useful in the identification of a NAP and may contribute to development of more effective cancer immunotherapies. This is urgently needed, as investigations into OSCC therapy in the field of tumor immunology are rare compared to those of malignancies with other origins.

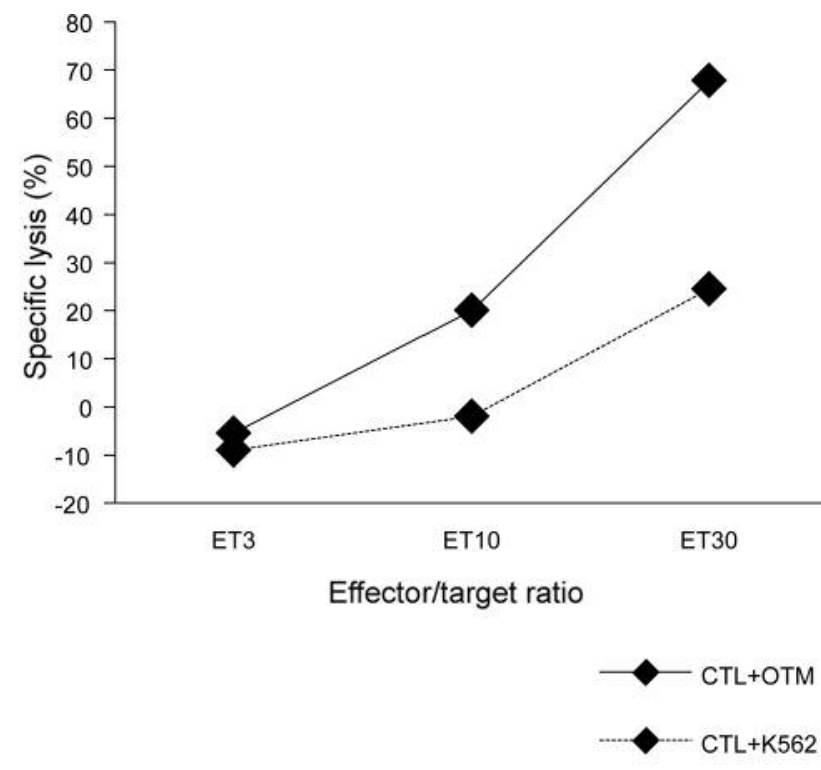

Figure 8. Cytotoxic activity of the CTL clone 3. In ET ratio 10 and ET ratio of 30, tumor-specific lysis against OTM cells was significantly higher than that against the K562 cells. The K562 cell line was used as negative control.

\section{Conclusion}

We successfully established a novel OSCC cell line and induced a specific CTL clone from autologous PBMCs of a patient with OSCC. The CTL clone exhibited tumor-specific cytotoxic activity against allogenic HLA-A24-positive oral cancer cell lines as well as the autologous OSCC cell line and recognized shared OSCC antigens. Further precise analysis of TcOTM-recognized antigens will provide important baseline information on as-yet-unknown NAPs in OSCC.

\section{Conflicts of Interest}

None of the Authors have any conflicts of interest to declare interest in regard to this study. 


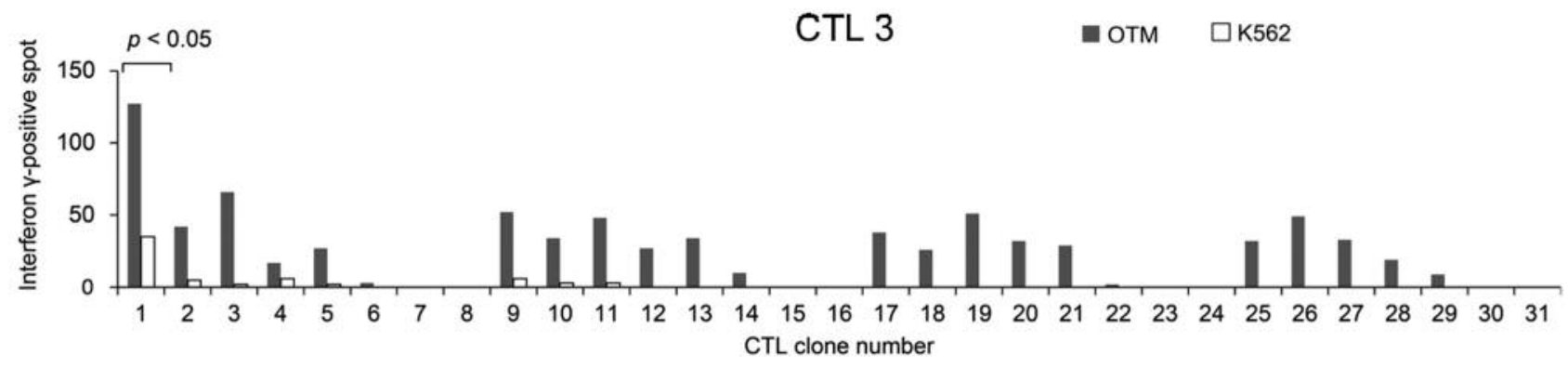

Figure 9. Limiting dilution of CTL clone 3 (CTL3). CTL3 was further subjected to limiting dilution to isolate a single clone. CTL3-1 showed the highest reaction and was, therefore, selected for use in subsequent experiments. The K562 cell line was used as negative control.

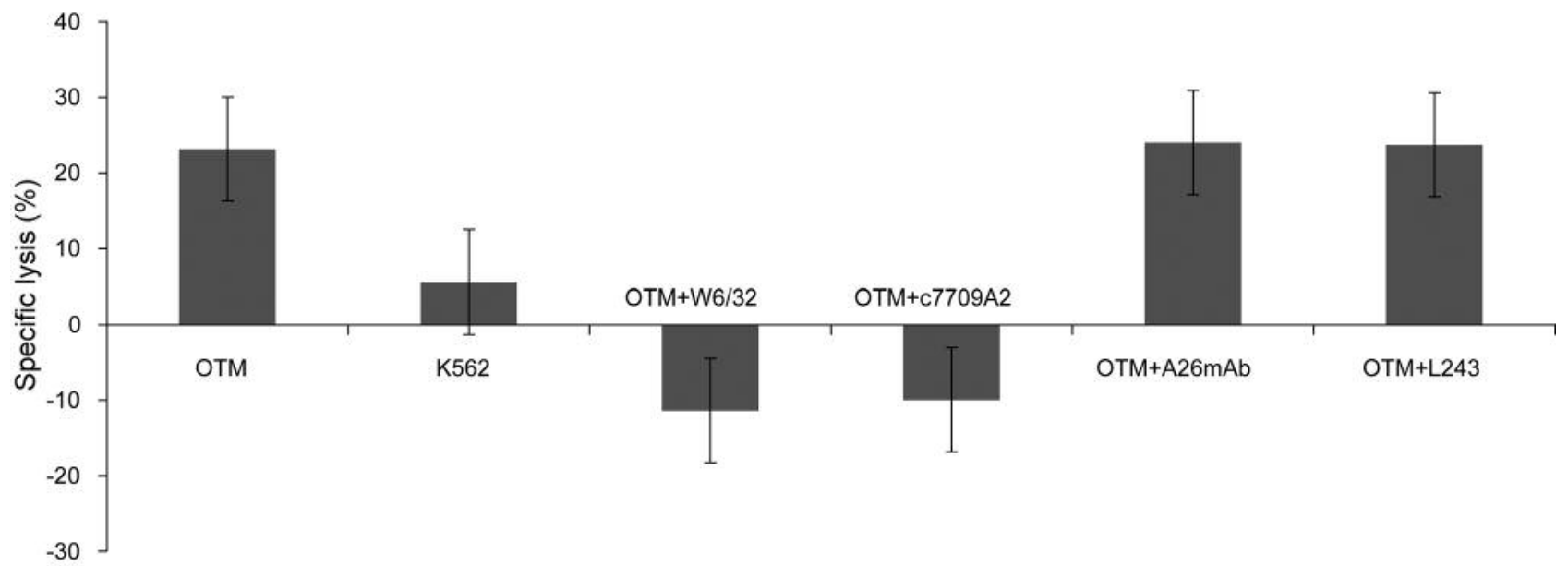

Figure 10. Blocking assays with monoclonal antibodies (mAbs) were performed with CTL3-1 to identify the human leukocyte antigen (HLA) restriction of elements using the lactate dehydrogenase release cytotoxicity assay. The use of W6/32 and C7709A2 antibodies reduced the cytotoxic activity of CTL3-1. The data indicate that CTL3-1 exerted its cytotoxicity by recognizing peptides bound to HLA-A24 of the OTM cells. The K562 cell line was used as negative control.

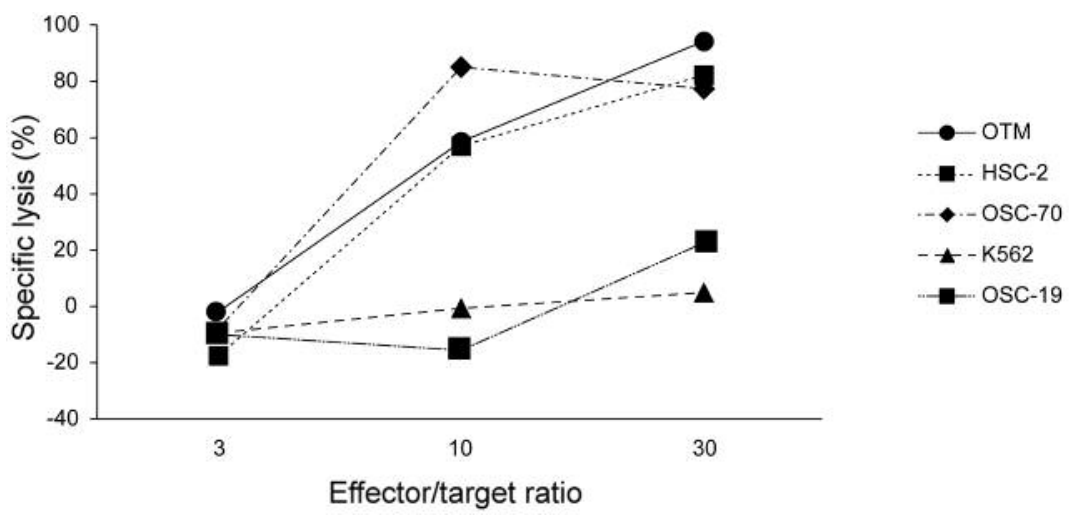

Figure 11. Cytotoxicity of CTL clone 3-1 against autologous and allogenic oral squamous cell carcinoma (OSCC) cell lines with various effector/target (E/T) ratios. TcOTM CTL cells were examined for their cytotoxic activity against OTM cells using the lactate dehydrogenase release cytotoxicity assay. Cytotoxic activity against the allogeneic OSCC OTM cells was examined. Allogeneic OSCC cell lines HSC-2 (HLA-24), OSC-70 (HLA-A24), and OSC-19 (HLA-A2) were used as target cells. CTL3-1 recognized allogeneic HLA-A24-positive OSCC cells. These data indicate that CTL3-1 recognized a shared antigen in an HLA-A24-restricted manner. 


\section{Funding}

This work was supported by JSPS KAKENHI (Grant Number 16K11729).

\section{References}

1 Warnakulasuriya S: Global epidemiology of oral and oropharyngeal cancer. Oral Oncol 45: 309-316, 2009.

2 Shah JP and Gil Z: Current concepts in management of oral cancer--surgery. Oral Oncol 45: 394-401, 2009.

3 Bonner J, Giralt J, Harari P, Spencer S, Schulten J, Hossain A, Chang SC, Chin S and Baselga J: Cetuximab and radiotherapy in laryngeal preservation for cancers of the larynx and hypopharynx: a secondary analysis of a randomized clinical trial. JAMA Otolaryngol Head Neck Surg 142: 842-849, 2016.

4 Soulieres D, Aguilar JL, Chen E, Misiukiewicz K, Ernst S, Lee HJ, Bryant K, He S, Obasaju CK, Chang SC, Chin S and Adkins D: Cetuximab plus platinum-based chemotherapy in head and neck squamous cell carcinoma: a randomized, double-blind safety study comparing cetuximab produced from two manufacturing processes using the EXTREME study regimen. BMC Cancer 16: 19, 2016.

5 Pai SI, Zandberg DP and Strome SE: The role of antagonists of the PD-1:PD-L1/PD-L2 axis in head and neck cancer treatment. Oral Oncol 61: 152-158, 2016.

6 Boon T, Coulie PG and Van den Eynde B: Tumor antigens recognized by T-cells. Immunol Today 18: 267-268, 1997.

7 Kawakami Y, Eliyahu S, Delgado CH, Robbins PF, Rivoltini L, Topalian SL, Miki T and Rosenberg SA: Cloning of the gene coding for a shared human melanoma antigen recognized by autologous T-cells infiltrating into tumor. Proc Natl Acad Sci USA 91: 3515-3519, 1994.

8 Marchand M, van Baren N, Weynants P, Brichard V, Dreno B, Tessier MH, Rankin E, Parmiani G, Arienti F, Humblet Y, Bourlond A, Vanwijck R, Lienard D, Beauduin M, Dietrich PY, Russo V, Kerger J, Masucci G, Jager E, De Greve J, Atzpodien J, Brasseur F, Coulie PG, van der Bruggen P and Boon T: Tumor regressions observed in patients with metastatic melanoma treated with an antigenic peptide encoded by gene MAGE-3 and presented by HLA-A1. Int J Cancer 80: 219-230, 1999.

9 Rosenberg SA: A new era for cancer immunotherapy based on the genes that encode cancer antigens. Immunity 10: 281-287, 1999.

10 van der Bruggen $\mathrm{P}$, Traversari C, Chomez P, Lurquin C, De Plaen E, Van den Eynde B, Knuth A and Boon T: A gene encoding an antigen recognized by cytolytic T-lymphocytes on a human melanoma. Science 254: 1643-1647, 1991.

11 Hirohashi Y, Torigoe T, Maeda A, Nabeta Y, Kamiguchi K, Sato T, Yoda J, Ikeda H, Hirata K, Yamanaka N and Sato N: An HLAA24-restricted cytotoxic $\mathrm{T}$ lymphocyte epitope of a tumorassociated protein, survivin. Clin Cancer Res 8: 1731-1739, 2002.

12 Miyazaki A, Kobayashi J, Torigoe T, Hirohashi Y, Yamamoto T, Yamaguchi A, Asanuma H, Takahashi A, Michifuri Y, Nakamori K, Nagai I, Sato N and Hiratsuka H: Phase I clinical trial of survivin-derived peptide vaccine therapy for patients with advanced or recurrent oral cancer. Cancer Sci 102: 324-329, 2011.

13 Kobayashi J, Hirohashi Y, Torigoe T, Michifuri Y, Yamamoto T, Tamura Y, Kamiguchi K, Miyazaki A, Yamaguchi A, Hariu H, Hiratsuka $\mathrm{H}$ and Sato N: Clonal diversity of cytotoxic Tlymphocytes that recognize autologous oral squamous cell carcinoma. Hum Immunol 70: 89-95, 2009.
14 Croker AK and Allan AL: Cancer stem cells: implications for the progression and treatment of metastatic disease. J Cell Mol Med 12: 374-390, 2008.

15 Morita R, Nishizawa S, Torigoe T, Takahashi A, Tamura Y, Tsukahara T, Kanaseki T, Sokolovskaya A, Kochin V, Kondo T, Hashino S, Asaka M, Hara I, Hirohashi Y and Sato N: Heatshock protein DNAJB8 is a novel target for immunotherapy of colon cancer-initiating cells. Cancer Sci 105: 389-395, 2014.

16 Morita R, Hirohashi Y, Torigoe T, Ito-Inoda S, Takahashi A, Mariya T, Asanuma H, Tamura Y, Tsukahara T, Kanaseki T, Kubo T, Kutomi G, Mizuguchi T, Terui T, Ishitani K, Hashino S, Kondo T, Minagawa N, Takahashi N, Taketomi A, Todo S, Asaka M and Sato N: Olfactory receptor family 7 subfamily $\mathrm{C}$ member 1 is a novel marker of colon cancer-initiating cells and is a potent target of immunotherapy. Clin Cancer Res 22: 3298-3309, 2016.

17 Nishizawa S, Hirohashi Y, Torigoe T, Takahashi A, Tamura Y, Mori T, Kanaseki T, Kamiguchi K, Asanuma H, Morita R, Sokolovskaya A, Matsuzaki J, Yamada R, Fujii R, Kampinga HH, Kondo T, Hasegawa T, Hara I and Sato N: HSP DNAJB8 controls tumor-initiating ability in renal cancer stem-like cells. Cancer Res 72: 2844-2854, 2012.

18 Yokoi T, Yamaguchi, A., Odajima, $\mathrm{T}$ and Furukawa, K: Establishment and characterization of a human cell line derived from a squamous cell carcinoma of the tongue. Tumor Res 23: 43-57, 1988.

19 Sato T, Sato N, Takahashi S, Koshiba H and Kikuchi K: Specific cytotoxicity of a long-term cultured T-cell clone on human autologous mammary cancer cells. Cancer Res 46: 4384-4389, 1986.

20 Kubo H, Abe J, Obata F, Nakajima H, Tsunoda M, Ogawa A, Nakayama S, Beck Y, Kohsaka T, Darrow TL, Abdel-Wahab Z, Saida $\mathrm{T}$ and Takiguchi $\mathrm{M}$ : Dual recognition of a human cytotoxic T-cell clone for melanoma antigens. Cancer Res 56: 2368-2374, 1996.

21 Maeda A, Ohguro H, Nabeta Y, Hirohashi Y, Sahara H, Maeda T, Wada Y, Sato T, Yun C, Nishimura Y, Torigoe T, Kuroki Y and Sato $\mathrm{N}$ : Identification of human antitumor cytotoxic T-lymphocytes epitopes of recoverin, a cancer-associated retinopathy antigen, possibly related with a better prognosis in a paraneoplastic syndrome. Eur J Immunol 31: 563-572, 2001.

22 Yamamoto E, Kohama G, Sunakawa H, Iwai M and Hiratsuka $\mathrm{H}$ : Mode of invasion, bleomycin sensitivity and clinical course in squamous cell carcinoma of the oral cavity. Cancer 51: 21752180, 1983.

23 Krause CJ, Carey TE, Ott RW, Hurbis C, McClatchey KD and Regezi JA: Human squamous cell carcinoma. Establishment and characterization of new permanent cell lines. Archiv Otolaryngol 107: 703-710, 1981.

24 Yokoi T, Hirata S, Nishimura, H, Miyakawa A, Odajima T, Kohama $G$ and Mochizuki Y: Some properties of a newly established human cell line derived from a oral squamous carcinoma. Tumor Res 25: 93-103, 1990.

25 Fukusumi T, Ishii H, Konno M, Yasui T, Nakahara S, Takenaka Y, Yamamoto Y, Nishikawa S, Kano Y, Ogawa H, Hasegawa S, Hamabe A, Haraguchi N, Doki Y, Mori M and Inohara H: CD10 as a novel marker of therapeutic resistance and cancer stem cells in head and neck squamous cell carcinoma. Br J Cancer 111: 506-514, 2014.

26 Kanaseki T and Shastri N: Biochemical analysis of naturally processed antigenic peptides presented by MHC class I molecules. Methods Mol Biol 960: 179-185, 2013. 
27 Kondo H, Sahara H, Miyazaki A, Nabeta Y, Hirohashi Y, Kanaseki T, Yamaguchi A, Yamada N, Hirayama K, Suzuki M, Hamuro J, Torigoe T, Takahashi N, Kohama GI, Ikeda H and Sato N: Natural antigenic peptides from squamous cell carcinoma recognized by autologous HLA-DR8-restricted CD4+ T-cells. Jpn J Cancer Res 93: 917-924, 2002.

28 Tsuruma T, Hata F, Torigoe T, Furuhata T, Idenoue S, Kurotaki $\mathrm{T}$, Yamamoto $\mathrm{M}$, Yagihashi A, Ohmura $\mathrm{T}$, Yamaguchi $\mathrm{K}$, Katsuramaki T, Yasoshima T, Sasaki K, Mizushima Y, Minamida H, Kimura H, Akiyama M, Hirohashi Y, Asanuma H, Tamura Y, Shimozawa K, Sato N and Hirata K: Phase I clinical study of anti-apoptosis protein, survivin-derived peptide vaccine therapy for patients with advanced or recurrent colorectal cancer. J Transl Med 2: 19, 2004.

29 Honma I, Kitamura H, Torigoe T, Takahashi A, Tanaka T, Sato E, Hirohashi Y, Masumori N, Tsukamoto T and Sato N: Phase I clinical study of anti-apoptosis protein survivin-derived peptide vaccination for patients with advanced or recurrent urothelial cancer. Cancer Immunol Immun 58: 1801-1807, 2009.

30 Tsuruma T, Iwayama Y, Ohmura T, Katsuramaki T, Hata F, Furuhata T, Yamaguchi K, Kimura Y, Torigoe T, Toyota N, Yagihashi A, Hirohashi Y, Asanuma H, Shimozawa K, Okazaki M, Mizushima Y, Nomura N, Sato N and Hirata K: Clinical and immunological evaluation of anti-apoptosis protein, survivinderived peptide vaccine in phase I clinical study for patients with advanced or recurrent breast cancer. J Transl Med 6: 24, 2008.

31 Yoshitake Y, Nishimura Y, Nakamura Y and Shinohara M: A clinical trial of multiple peptides vaccination for advanced head and neck cancer patients induced immune responses and prolonged OS. Oncoimmunology 4: e1022307, 2015.

32 Ikeda N, Kojima H, Nishikawa M, Hayashi K, Futagami T, Tsujino T, Kusunoki Y, Fujii N, Suegami S, Miyazaki Y, Middleton D, Tanaka H and Saji H: Determination of HLA-A, $\mathrm{C}$, - B, -DRB1 allele and haplotype frequency in Japanese population based on family study. Tissue Antigens 85: 252-259, 2015.
Received June 5, 2017

Revised July 3, 2017

Accepted July 5, 2017 